\title{
The electronic chalkboard
}

\author{
JAMES E. SPIVEY and PAMELA JACKSON-SMITH \\ University of Kentucky, Lexington, Kentucky
}

\begin{abstract}
The present paper describes "the electronic chalkboard" (TEC), a teaching innovation made possible by the recent development, under a FIPSE grant to CONDUIT, of specialized instructional software. The instructional power of TEC casts the computer in the role of catalyst in the student-teacher dyad and leads to the emergence of the more powerful student-computerteacher triad. Relevant educational principles and CAI techniques that should ensure the intelligent use of TEC are discussed.
\end{abstract}

Although an increasingly large number of teachers are paying lip service to computer-assisted instruction (CAI), much of the present-day usage of CAI insults the potential of the computer and belies the hardware revolution of the past 8 years. Further, most extant CAI threatens to turn many students against not only CAI, but computers as well, primarily because most software is unimaginative and, except to the dedicated computerphile, boring. Objective surveys often reveal an absence of the assumed preference of students for CAI over more traditional modes of instruction. In spite of countervailing demand characteristics of ten implicit in these surveys, an actual preference for more traditional approaches sometimes is found. It is the contention of the present paper that those writing CAI have yet to apply the full range of instructional techniques that the same individuals employ in the classroom. That is, to be successful, CAI should emulate a good teacher in being highly interactive, dynamic, and varied.

Heretofore, CAI has occurred almost exclusively in departmental or university (computing center) labs wherein the student and the machine interact. Although such dyads are needed and should be continued, even better use can be made of the computer as a catalyst for the critical student-teacher interaction that occurs during lectures. It is in the lecture format that the greatest variety of CAI usage can be enjoyed. Presently existing software is not appropriate to this student-computer-

This paper is based on a CAI research and development project supported by FIPSE (Fund for the Improvement of Postsecondary Education) Grant G007905216 to CONDUIT, presently the major nonprofit publisher of postsecondary educational software. N. John Castellan, Psychology Editor for CONDUIT, serves as Director of the Psychology Task Force, whose other members are Darrell Butler, Douglas Eamon, Philip F. Spelt, and James E. Spivey. The project is described in detail by Castellan (1984). Special appreciation is expressed for the support and expert counsel provided by Pete Trotter, Associate Director of CONDUIT. Sole responsibility for statements contained in this paper lies with the authors. Requests for reprints or additional information should be sent to James E. Spivey, Department of Psychology, Kastle Hall, University of Kentucky, Lexington, KY 40506. teacher triad; consequently, one needs to write sof tware with this specific educational mode in mind (cf. Butler \& Kring, 1984).

One way of accomplishing this goal is through the use of "the electronic chalkboard" (TEC), a teaching method that employs a number of recently designed subroutines called AuthorAssist. AuthorAssist's development is reviewed by Castellan (1984); the software is described by Eamon (1984); and an illustration is given by Spelt (1984). The primary focus of the present paper is on the principles governing the design and application of this software as TEC.

Briefly, TEC provides for the replacement in the lecture hall of the isolated, unresponsive, fixed-format, traditional chalkboard with a computer-controlled display. This display involves a number of independent screen ports among which information can be easily transferred. Consequently, the teacher can maintain constant physical contact with students while keeping the class abreast of the overall lecture outline, supporting points and elaborations with appropriate graphic displays and simulations. All of this is easily set up and manipulated in an interactive mode in response to student comments and questions. Students are invited to participate by manipulating information in one or more ports. Because more than one port can be displayed at a time, the instructor can demonstrate the interrelationship of apparently in. dependent material developed in the separate ports.

Although all of this sounds very promising, the task for the instructor is not as simple as it might appear. Just as much of the educational software available today is worthless, so also might TEC, though a good notion, soon become a tiring bore if proper attention is not paid to good instructional design. Thus, the teacher, when designing or using TEC, might refer to a theory such as Gagne's, as well as to the specific CAI techniques through which the theory might be articulated (Castellan, 1983; Gagne, 1974; Gagne \& Briggs, 1979).

Many of the authors' ideas concerning the use of TEC are consistent with, and some were stimulated by, Gagne's educational theory concerning the nine steps in the teaching process (Alesandrini, 1982; Alesandrini, 1983; 
Gagne, Wager, \& Rojas, 1981). Consequently, the discussion of TEC will be cast within the framework of Gagne's theory.

\section{ATTENTION AND MOTIVATION}

Gagne's first step in the teaching process is a virtual invitation to any imaginative computerphile. First, we must gain and establish control over the learner's attention, and we must motivate him/her to learn. Picture a large lecture hall in which are seated 200 or more students. The teacher begins the lecture; but what might the students be doing? Most are probably beginning to open their notebooks and search for pencils or pens; some may be folding up newspapers or finishing conversations. The instructor-especially of a large class-often has trouble getting undivided attention. Important introductory remarks are lost, and some students subsequently fail to understand the remainder of the lecture.

Compare this scene with one involving the same instructor, class, and room, but with a very important addition. This time the instructor has a microcomputer with AuthorAssist. The micro is linked to a large screen in the front of the room or to several monitors placed about the room. Through the use of an interesting animated introduction, the students' attention is captured and is focused on the topic. It is obvious that with computer-controlled displays this instructor begins his/her lecture on a firmer footing than with more traditional methods. Note that the physical setup appears similar to instructional television or movies; but this similarity is only apparent, as we shall see later in this paper.

Suggestions and admonitions relating to Gagne's first step include the following. First and foremost, although we are using advanced technology to gain the students' attention, the instructor must always remember that the center of attention should be the students and not the technology. The latter must serve the former, and not the reverse, as often seems to be the case. To ensure that this point is understood by the students, they should be made to feel that they are to some extent in control of the technology. Although this can be accomplished best through student stations (terminals) individually gated through the instructor's station, this approach is not financially practical. There are two other possibilities. One is that terminals can be set up at each of several locations around the room. A student, to participate, could go to one of these stations. This configuration also seems impractical because of the disruption caused by students' moving about the classroom. A workable alternative is for the students' responses to be keyed in by the instructor at his/her station. Our preference is to have one large screen display at the front of the room, rather than monitors spread about the classroom. The single screen keeps the students' attention directed toward the instructor, who can be seen along with the screen. This maintains the true triad.
Throughout the presentation, some other cautions need to be observed. In seeking interesting displays, the instructor obviously will use animation and will integrate visual and auditory learning through the use of color and sound. However, teachers employing CAI often end up with screen displays that are too busy and confusingespecially to the less gifted or more anxious students. Large simple displays are not only more easily seen at a distance -an important consideration in a large lecture hall--but also provide for more effective communication.

\section{LECTURE OBJECTIVES}

Gagne's second step in the teaching process is to inform the learner of the lesson's objectives. Many teachers, in concert with Gagne's suggestions, like to present an outline of the lecture along with the overall objectives. With a traditional chalkboard, the teacher often must erase the outline in order to have chalkboard space on which to present the details of the lecture. Removal of the outline is unfortunate, not only because the objectives and outline are important as part of the motivational process in establishing the goals of the lecture, but also because they facilitate notetaking and comprehension. TEC solves this problem by reserving a port in which the key points of the outline are presented; that is, the instructor may choose to permanently fix a very brief outline in a port, or he/she may slowly scroll through a more elaborate outline.

\section{PREREQUISITES}

As a third step, we need to ensure that the students possess the necessary prerequisites. Perhaps this is only to review the last lecture and to tie it into the present one; or perhaps the instructor is requiring students to reach further back in time, as, for example, to an earlier statistics course. Either review is a simple task for TEC. The screen can be cleared (remember, the objectives are in one port), or a second port, within which the appropriate material can be presented and discussed, can be opened. The extent of the review can depend on student performance during the discussion. This stage of ensuring prerequisites should involve hierarchically branched review programs. Branches to be pursued would depend on student responses. This may be the first time during the lecture when students are asked to respond. Also, this interaction establishes early in the lecture the true student-CAI-teacher triad that we seek.

\section{NEW INFORMATION}

Gagne's fourth step deals with the presentation of new material. Throughout the lecture, the objectives or outline should be kept in view in one port. Due to the limited size of the port, the lecturer may wish to identify the preceding, present, or succeeding points of the outline with a bullet. 
With the use of TEC, the instructor can attend to good pedagogy more closely than is possible with a traditional presentation. Two characteristics of student learning need to be stressed. The first is that, during a lecture, students are processing several different units and types of information-either in a parallel fashion or in a timesharing mode. The second characteristic of student learning is that the various elements of the lecture are being processed at different rates and, perhaps, in different orders by different students. Although the teacher may present a definition first and then give an example, many students may choose to process the material in the reverse order. Also, some may need a long time to understand a definition, but may quickly and intuitively grasp the application; for other students, the opposite may be true. With TEC, these individual differences are easily handled. Consider an example in which four ports are employed. In the top left port is an abbreviated lecture outline; in the top right port is a more detailed outline of the point being presently discussed. In the lower left port is defined a novel concept that is crucial to an understanding of this part of the lecture. Finally, the lower right port contains an animated example of the concept or an application or extension of the lecture topic being discussed.

The simultaneous presentation of these different types of information not only allows students to process the parts in any order they wish, but also allows them to rehearse and to recheck other parts as uncertainties are generated by another part. Also, the mutual reinforcement of the learning process provided to each part by the other parts of the whole should result in greater learning. Other strategies are possible and are limited only by the teacher's imagination. The main point is that students will be able to view simultaneously several key elements of a whole and, perhaps, understand the material at a level previously not possible.

Student learning also is facilitated if a particular kind of communication always appears in the same port, for example, the outline in the upper left port. This does not mean that the upper left port is used only for the outline; it means, if and when an outline is given, it appears in the upper left port. Note also that the screen may involve different numbers of ports at different points in the lecture, and that the entire screen occasionally may be dedicated to one large animation.

\section{ELABORATION}

Gagne's fifth step is the facilitation of learning by means of elaboration. This obviously is far better done with computer-generated graphics and animation than with traditional lecturing techniques. In generating these lively displays, however, we must not allow ourselves to become absorbed in a technological tangent, but must continually show. the students how the details fit into the overall picture, or how new knowledge or elabora- tions fit with old knowledge. Discrimination, as well as generalization, should be taught because the learning of difficult concepts is facilitated by the presentation of both examples and nonexamples.

\section{PERFORMANCE AND FEEDBACK}

Gagne's sixth step, eliciting performance, and the seventh step, providing feedback, are, due to the highly interactive nature of our teaching paradigm, intimately intertwined with the other steps. The constant involvement of students is necessary if the TEC concept is to work. An active learner learns best partly because attention and motivation are guaranteed and because the teacher has a basis for providing appropriate guidance or feedback.

It is the active posture of the learner that separates TEC from movies and instructional television. The involvement of one of the authors in a 3-year instructional television project convinced him, after the expenditure of a lot of money and time, that an old-fashioned charismatic lecturer was better than instructional TV. Students were frustrated by the TV's precluding their participation. Of course, TEC may be misused by some instructors and result in the same sort of frustration.

Following this reasoning, care should be taken to keep the participation of each student brief. This is not to advocate that questions be answered with a yes or a no. On the contrary, the required responses must be specific and selective to ensure true understanding. But the interactions of students with TEC must be relatively brief and fast-paced in order that many students may participate.

Note that students can be led to interact with each other through TEC. For example, different students can enter different elements or parameters of a Pavlovian conditioning simulation. The students can all participate in the same port, or each student can have his/her own port to work with and someone (the instructor or another student) can then put it all together. Here again, the variety of participation possible is limited only by the imagination of the teacher and the students. Students continually will come up with desired interactions that will require modifications of the software. The carrying out of those modifications will be perhaps the most effective reinforcement for the students' assuming some responsibility for their education.

\section{ASSESSMENT, CONSOLIDATION, TRANSFER}

Gagne's eighth stage, assessment, and the ninth, facilitation of retention and transfer, are collapsed into one large stage due to the nature of our teaching paradigm in which the assessment of student understanding is synonymous with the interactive nature of TEC. However, if it becomes possible for universities to have keyboards at each student's station, it might be helpful 
to have a brief quiz at the end of the lecture. This quiz need not be graded, but merely used to provide feedback for the instructor. He/she may find that those who did not participate during the lecture are totally lost. With individual student stations, if they also included monitors, correct answers and guidance could be provided to each individual.

It is hoped that teachers will save time at the end of the lecture to ensure consolidation and to elicit transfer. To this end, the lecture objectives or outline should be reviewed and extrapolations to new or different situations should be elicited from students. This is also where good simulations can be used to illustrate the applications of the lecture information.

\section{SUMMARY}

In sum, TEC provides a framework within which is elicited the most vigorous and varied student participation, and within which, consequently, the educational process is focused on the student.

\section{REFERENCES}

Alesandrini, K. L. (1982). CAI should differ from tradition. Electronic Education, 2(15), 22-23.

Alesandrini, K. L. (1983). Instructional design for CAI tutorials. Unpublished manuscript.

Butler, D. L., \& KRING, A. M. (1984). Survey on present and potential instructional use of computers in psychology. Behavior Research Methods, Instruments, \& Computers, 16, 180-182.

Castellan, N. J. (1983). Strategies for instructional computing. Behavior Research Methods \& Instrumentation, 15, 270-279.

Castellan, N. J. (1984). A model for courseware development in psychology. Behavior Research Methods, Instruments, \& Computers, 16, 165-167.

EAmon, D. (1984). Concepts underlying the development of modules. Behavior Research Methods, Instruments, \& Computers, 16, 168-171.

GaGne, R. M. (1974). Essentials of learning for instruction. New York: Holt, Rinehart \& Winston.

Gagne, R. M., \& Briggs, L. J. (1979). Principles of instructional design (2nd ed.). New York: Holt, Rinehart \& Winston.

Gagne, R. M., Wagner, W., \& Rojas, A. (1981). Planning and authoring computer-assisted instruction lessons. Educational Technology, 21(9), 17-26.

Spelt, P. F. (1984). Overview and examples of instructional modules. Behavior Research Methods, Instruments, \& Computers, 16, 176-179. 